\title{
General Risks Faced By China's Foreign Cultural Trade
}

\author{
Tang Lijing
}

Communication University of China, Beijing, China

alicetang1988@126.com

\begin{abstract}
Under the strong promotion of the "cultural power" policy, with the continuous development of China's cultural industry, foreign cultural trade has developed rapidly, but the risk management awareness of the entire industry is relatively weak, and the risk management system has not yet been established. Analyzing general risks will help to raise the awareness of the risks of China's cultural industry and foreign cultural trade practitioners, keep pace with the industry in the world, improve the ability to resist risks, and promote the development of the industry.
\end{abstract}

Keywords: foreign cultural trade, risk

\section{我国对外文化贸易面临的一般性风险}

\author{
汤丽晶
}

中国传媒大学, 北京, 中国

alicetang1988@126.com

\section{摘要}

在 “文化强国” 政策的有力推进下，随着我国文化产业的不断发展，对外文化贸易发展迅速，但是整 个行业的风险管理意识较为淡薄，风险管理体系尚未建立，因此通过审视对外文化贸易面临的一般性 风险，将有助与提高我国文化产业和对外文化贸易从业者的风险意识，与世界同业看齐，提高抗风险 能力，促进行业发展。

关键词：对外文化贸易风险

\section{1. 前言}

我国文化产业有巨大的发展潜力，但是文化产业的 高投入和高收益为企业的经营发展带来高不确定性风 险，尤其是从事对外文化贸易的企业面临的风险更具有 不确定性。如果不能很好对风险进行管理，一旦发生损 失, 则会付出很大的成本。大量的资源集聚, 容易引起 连锁反应, 引起发生损失的高风险性和损失发成程度较 高的危险性。

\section{2. 政治风险}

政治风险也称作国家风险，指由于国家性事故如政 治因素、社会因素和国家贸易政策变动等所造成的国际 贸易风险，是影响对外文化贸易的重要风险之一。[1] 一国政治发生变化则必然影响到其他方面, 可谓牵一发 而动全身。
政治因素引发贸易中断风险。由于政治因素和社会 因素引发的政治风险通常能够影响到进口国的国家稳 定，当一国政局面临巨大变动时，对非政治层面的考虑 则让位于政治层面。在政治利益优先的情况下, 其他国 家的进出口贸易属于次要考虑因素。对外文化贸易面临 此种因素造成的突然中断甚至终止, 且面临延迟支付风 险、损失不能追偿风险。以非洲索马里为例, 由于国内 政局极不稳定, 随时都有政府违约风险, 几乎没有国家 愿意与之进行对外文化贸易。即使拥有强大文化软实力 的美国, 也鲜有向索马里出口文化产品。对外文化贸易 企业承受不了由此产生的血本无归的风险, 因此在进行 产品出口时会重点考虑政治因素。

政治因素引发政策变动风险。虽然贸易合作组织不 断增加, 国际贸易条约、多边或双边贸易条约不断制 定，但是国家间的贸易摩擦并没有随之减少反而不断加 剧，各国均利用贸易政策或制定特殊的贸易政策通过出 口退税、外汇管制、歧视性贸易政策、反倾销、反补贴 等形式或隐性的非关税贸易壁垒进行竞争和约束。同 时, 一旦涉及到国家利益, 可随时通过修改贸易政策、 
交流，在翻译沟通的构成中，由于相关人员的知识储 备、认识能力、翻译等因素的影响, 可能带来语言理解 上的偏差和错误。因语言反映到文化上的不同, 使得文 化差异制约着民族之间的交往, 在交流中不可避免地产 生分歧, 影响贸易双方对文化产品的认知。

宗教矛盾的风险。宗教本身不是风险, 但在特定条 件下, 往往成为不幸事件发生的导火索, 并成为事件扩 大的诱因。全世界存在多种宗教, 每个国家或地区对宗 教的尊崇程度不同, 有的国家宗教信仰氛围十分浓厚, 只承认一种宗教或对其他宗教怀有很强的敌意。当对外 文化贸易遇到教派对立、宗教纷争时, 未能考虑周全或 遭遇不好的机会，难免会遭遇损失，甚至血本无归。

制度因素的风险。对外文化贸易企业在走出去的过 程中受到国际相关贸易规则的约束, 但是更多的会遇到 进口国家规则的约束。因为不同国家的政治体制和社会 制度不同, 增加了对国际规则的认同难度, 加之法律制 度的不健全和不完善, 影响对贸易规则和贸易文化的认 知, 为企业带来经济风险。

习俗观念的风险。不同国家的文化的表现形式之一 就是难以用语言描述的风俗习惯。这些风俗习惯不伤害 公益良俗, 不有违贸易规则, 但是会产生对某些观念和 产品自觉的抵制, 因此为对外文化贸易带来不确定性风 险。

\section{5. 商业环境风险}

操作风险。进行对外文化贸易必须面临不同国家和 地区不同的商业环境, 在此环境中操作风险是突出的风 险之一, 并以专业技术、专业人才、商业信息共享平台 方面的操作风险为典型。专业技术已经成为推动经济发 展和市场改革的重要动力。新技术、新手段的应用直接 影响企业的产品质量和运营效率。由于我国不同文化行 业、企业的技术应用程度差异巨大, 我国对外文化贸易 面临信息技术应用范围不广、应用程度不深的风险。此 外, 我国文化产业的专门人才紧缺, 从事对外文化贸易 的人才较少。没有合适的管理人员和技术人员, 则任何 企业的发展都会成为空谈。在世界经济联系日益紧密的 今天, 人才的流动性日益提高, 我国企业还要面临同世 界企业竞争优秀人才的风险。我国关于文化产业人才优 惠和培养政策尚不清晰和完善, 人才交流沟通的体制机 制尚未建立, 大型企业人才过于集中, 中小企业缺少培 养人才的实力, 对外文化贸易企业面临人才断层的风 险。最后, 信息不对称是对外文化贸易企业面对的严重 问题之一。我国对外文化贸易面临着信息获取不充分、 不及时的风险, 在国际市场信心和出口信息的搜集、梳 理、分析、使用上都存在许多问题, 缺少服务于对外文 化贸易企业的大数据信息和及时信息, 相关企业缺少了 解权威信息的途径和手段。在出口平台、渠道和交易平 台方面, 参加国内外重要的国际文化产品展会的机会稀 缺, 对外文化贸易企业以新设、收购、合作等形式在国 外进行文化领域的投资合作的经验和途径不多, 国际营 销网络不成熟, 部分优秀的对外文化贸易企业面临有钱 
予文化产品特殊待遇的条款。首先, 在 WTO 的现有规则

无处投、有钱没有好项目的风险。

商业模式创新不足风险。文化产品走出去需要成熟 的商业模式做保障。以美国为例, 文化产业通过科技、 资本推动内容创造价值, 以创意为核心, 运用科技手段 将其现实化、可操作化，进而引用资本通过高度商业化 的运营模式开拓国际市场。美国的创意产业十分发达, 对创意的深度挖掘到位, 《花木兰》、《功夫熊猫》等原 型虽非美国土著, 但是美国企业能够将外国元素通过创 意改变成为影片、衍生品, 使之为全世界人民所接受, 并获得高额利润。我国文化产业商业化资本运作模式单 一, 对文化产品的干预程度过多或过少, 参与国际市场 竞争的力度和积极性不足, 我国对外文化贸易面临资金 不足、资金参与程度不适度的风险。

\section{6. 金融风险}

汇率风险。用于国际贸易的结算货币一般以价格坚 挺的美元为主, 因此交易双方进行清算时, 汇率受到本 国货币同美元的汇率关系的影响，外汇市场的涨跌程度 影响了具体业务的盈收。无论使用何种货币作为结算货 币，对外文化贸易存在着本币和外币的折算比率问题。 国际外汇市场的波动会影响到该比率的变动, 企业的收 入随之波动, 企业的外币支出、收入业务也会受到影 响, 进而影响企业的结汇业务, 因此导致企业面临汇率 变动带来的风险。一旦外币升值, 本币贬值, 则会造成 实际支付的成本增加, 企业利润降低。

融资风险。文化产业本身具有高投入、高收益风 险, 因此对外文化贸易面临着融资难、融资质量不高的 风险。首先, 面临融资渠道不充分的风险, 收益的不确 定性严重影响了投资方对文化产业的兴趣。其次, 面临 资产评估体系不完善、信用担保体系不完善的风险。第 三，面临融资成本高、融资规模小的风险。最后，面临 融资质量不高的风险。

投资风险。国家通过政策和中介，鼓励中小企业通 过跨国投资实现产业转移和目标国产品销售, 绕开贸易 壁垒, 替代出口贸易, 将文化产业的成熟产品打入国际 市场并逐步扩大贸易规模。通过扩大出口、增加对外投 资等途径, 扩大中国文化产品和服务在国际市场上的份 额。[2]通过对外投资, 在海外寻求发展机会, 成长为跨 国公司。

\section{7. 国际组织规则冲突对文化贸易造成的风险}

对外文化贸易的发展离不开国际条约的约束, 在 WTO 等国际组织中, 对外文化贸易面临着大量的机遇, 也面临 着风险和挑战。WTO 的现行规则并不给予文化产品特殊待 遇的条款。《文化多样性宣言》和《文化多样性》公约等 又呼吁承认文化产品的特殊性, 给予特定的保护和支持。 文化产品面对不同的风险寻求着不同的对策。

WT0 对文化贸易的一般性待遇规定。尽管文化产品在 内容或形式上拥有特殊性, 但是 WTO 的现行规则并不给
中，货物贸易法律制度与服务贸易法律制度是相互独立 的, 但并不存在如何对货物和服务进行分类或定性的专 门标准。[3]因具体事件及抗辩理由的不同, 一旦 WTO 认 为涉案文化产品为货物贸易, 则成员国不得申请豁免最 惠国待遇等条款, 反之, 如果 WTO 认为涉案文化产品为服 务贸易, 则成员国有申请豁免最惠国待遇的权力。2009 年 12 月, WTO 上诉机构裁定中国在中美出版物和音像娱乐 制品案中败诉, 中国承诺修改相关文化贸易措施。历时三 年的拉锯战使得处于文化贸易弱势地位的中国不得不接 受促进自由贸易的裁定, 并在今后的文化贸易中遵守此 判例。其次, 除 GATT 第 4 条关于电影片进口配额的规定 外, WTO 现行规则中并不存在对属于货物的文化产品给予 特殊待遇的条款, 也不存在文化例外条款, 各成员国不能 以文化为理由采取或维持贸易限制措施。最后, WTO 并不 存在将自身规则与其他国际规则联系起来的规则。从 WTO 的实践看, 它承认其他国际规则例如《世界文化多样性宣 言》、《保护和促进文化表现形式多样性公约》的有效性, 但是在其适用性上保持谨慎态度, 或者说实行 GATT 及 GATS 优先原则。

保障文化多样性的贸易措施与 WT0 规则冲突带来的 风险。为保护文化主权及国内文化市场，一国可以在 WTO 框架内, 从多个方面采取文化贸易保护限制措施, 此种措 施可以为我国对外文化贸易带来多方面的风险。第一，一 国在加入 WTO 进行贸易谈判时, 可以对文化产品进行明 确约定。在货物贸易方面, 如果一国在开放谈判中, 明确 约定对属于货物的进口文化产品维持较高的关税, 或实 行限额或配额, 那么我国低附加值的文化产品则会面临 关税增加、收益和利润会大幅下降的风险。在服务贸易方 面, 一国可以明确约定属于服务贸易的文化产品, 并在开 放谈判中, 将其列在最惠国待遇豁免清单, 那么我国文化 特色较为明显或具有领先优势技术的高附加值文化产品 则会面临无法打开对方市场或不公平待遇的风险。第二, WT0 成员国可以约定 GATT 关税减让表之外文化产品的关 税或税费。第三, WT0 成员国可以实施进口许可程序，通 过合法措施达到限制进口的目的, 若进口国实行批准制 或许可制, 要求进口产品符合本国文化、宗教信仰、道德 或风俗习惯等。第四, WTO 成员国根据《与贸易有关的知 识产权协定》（TRIPS），有义务对其他缔约国的知识产权 给予保护。但若为保护本国文化产业从而以保障文化多 样性为由, 一国可能对进口的其他成员过的文化产品不 给予或给予低标准的知识产权保护, 则我国对外文化贸 易面临这著作权、商标权、地理标志、表演人邻接权等不 能得到有效保障的风险。第五, WTO 成员国可以根据《补 贴与反补贴措施协定》中的规定, 采取符合第八条的补贴 措施, 则有义务不对其他成员造成不利影响和严重损害。 [4]基于此, 即使该成员国不损害进口国利益, 但是本身 采取的补贴或奖励, 就已经为进口国造成了不公平的市 场环境, 导致进口国面临成本上升、利润下降的风险。第 六, 一国可以在投融资领域, 约定进口文化产品的收益或 外国投资者的收益用途。对于我国参与投资的文化产品 来说, 可能面临无法自由支配预期收益或收益率低的风 险。 
随着经济全球化的发展，全球贸易市场一体化程度 日益加深，各国企业均有全球化、跨国化发展的需求， 也逐渐具备整合全球资源、进行跨区域配置资源的能 力。[5]因此对外文化贸易企业面临的一般性风险是普 遍性的、全球化的风险, 对于一个企业而言, 因单一风 险引起的其他风险, 或某种风险造成的损失将连锁发 生, 风险管理的难度将越来越大。各国的政治、法律、 文化、商业环境、金融因素不断发生变动, 由此引发的 风险也随之变动, 这些风险变动加大企业风险决策的难 度、增加风险管理的成本。企业在短时间内难以适应各 国各式各样的变化, 一旦进行风险决策后, 则对企业后 期经营产生深远化影响, 加大企业转型和适应难度。因 此, 建议对外文化贸易企业能够提高风险意识, 尽快建 立风险管理体系, 加强对国际市场的了解, 增强国际竞 争力.

\section{REFERENCES}

[1] Chi Ying. Research on the International Expansion of Chinese Cultural Industry. Northeast Normal University, Ph.D. Thesis, 2014.

[2] Zhao Youguang, Sheng Beibei. Development Strategy and Implementation of the Export-oriented Internationalization of Chinese Cultural Industry [J]. International Trade, 2008 (10): 32-38.

[3] Chen Weidong, Shi Jingxia. The Dilemma and Outlet of Cultural Policy Measures under the WTO System: Thinking Based on the "Sino-U.S. Publications and Audiovisual Products Case". French Business Research. 2010-07-15

[4] Yao Xinchao. Conflicts between safeguarding cultural diversity and WTO rules and suggestions on coordination measures. International trade issues. 2008-06-15

[5] He Chunliu, Ding Wenyao. Anticipation and Management Measures of International Trade Risks of Chinese Enterprises. Special Zone Economy. 2017-03-25 